\title{
THE IMPORTANCE OF DOWNHOLE SAFETY MONITORING SYSTEM IN THE OIL DRILLING
}

\author{
Zhang Zhiliang \\ School of Mechanical and Electrical Engineering. \\ Southwest Petroleum University, Chengdu, Sichuan, China \\ Engineering technology research institute. \\ China petroleum west drilling engineering Co. Ltd. Urumqi 830011, China \\ Yi Ming \\ Engineering technology research institute. China petroleum \\ west drilling engineering Co.,Ltd. Urumqi 830011, China.
}

\author{
Liu Qiang \\ School of Mechanical and Electrical Engineering. \\ Southwest Petroleum University, \\ Chengdu, Sichuan, China
}

\begin{abstract}
During the drilling process of oil drilling, because of the complexity of geological conditions and many uncertain factors, in many cases, the most effective measures cannot be taken in time to solve the drilling safety problem. Downhole safety monitoring system is an effective technical mean to reduce the risk of drilling, the system can predict the potential risk issues in the process of drilling by collecting all kinds of downhole and surface real-time data information, so that the operator can give timely measures by combining with the ground terminal system to reduce or eliminate the risk. Then, the safety problem drilling of complex deep wells can be effectively solved and the drilling efficiency can be greatly improved. This paper purports to expound the important role of the system by analyzing the common drilling risks in the process of drilling complex strata and explaing the working principle of the downhole safety monitoring system. In so doing, this paper intends to argue that the downhole safety monitoring system is very important in the oil drilling.
\end{abstract}

Keywords - Oil drilling, Drilling risk, Downhole safety monitoring system, Importance

\section{INTRODUCTION}

Oil is an important strategic resource, which is of great significance to the development of the country. At present, the unproven petroleum resources in China are about 85 billion tons, of which $73 \%$ are buried in the deep layer[1], moreover, the geological conditions are complicated and there are so many uncertainty factors encountered in the drilling process. In many cases, the most effective measure cannot be taken to reduce the drilling risks because the downhole topography and drilling conditions cannot be obtained promptly and accurately during drilling. This circumstance not only causes loss circulation frequently, but also leads to hole collapse and sticking seriously, resulting in frequent drilling accidents. Meanwhile, it wastes a lot of working time and cost, so that the efficiency of exploration and development is also greatly affected. To some extent, drilling technology in complex areas has become a key technical bottleneck restricting oil and gas exploration and development in this area. The effective monitoring and prevention of drilling risks has become an important link in the exploration and development of oil and gas .

Downhole safety monitoring system is an effective technical way to reduce underground safety accidents, the system through pre-drilling analysis and evaluation, monitoring with drilling, surface data acquisition and comprehensive analysis software platform to collect all kinds of downhole and surface real-time information. Then, the system timely obtains downhole complex formation conditions and complex working conditions to accurately identify downhole conditions and predicts the possible risks in drilling process. Finally, it can analyze and feedback solutions and give measures to reduce or eliminate risks, so as to effectively solve the safety problem of drilling complex deep wells and to achieve the aims of reducing the drilling risk, improving the drilling efficiency and the reliability of the combination of the drilling tools and optimizing the drilling measures. The downhole safety monitoring system has important engineering significance for the safe drilling of complex deep and ultradeep wells and the production of oil.

At present, foreign downhole safety monitoring systems are represented by the No Drilling Surprise(NDS) System of Schlumberger, the Advanced Data Transfer(ADT) System of Halliburton and the Downhole While Drilling Diagnosis System(copilot) of Baker Hughes. In China, the downhole safety monitoring system is mainly represented by the Downhole Real-time Safety Monitoring System developed by the Institute of drilling Engineering and technology in Western drilling of PetroChina. The application of downhole safety monitoring system effectively reduces the downhole safety risk in oil drilling, greatly improves the drilling efficiency, ensures the safety of the life and property and contributing to the exploration and development of deep and ultra-deep wells. 


\section{International Journal of Engineering Applied Sciences and Technology, 2019 \\ Vol. 4, Issue 7, ISSN No. 2455-2143, Pages 10-14 \\ Published Online November 2019 in IJEAST (http://www.ijeast.com)}

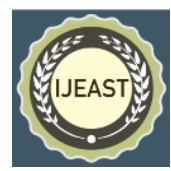

Section Conclusion: in this section, analyzes the present situation and technical pain of the development of oil resources in China, and puts forward the challenges of oil exploitation at the present stage and in the future. introduces the main functions of the downhole safety monitoring system, briefly explains the working principle, determines the functions that can be realized, and strengthens the position in the oil drilling. At the same time, the related research of downhole safety monitoring at home and abroad is analyzed.

\section{COMMON DRILLING RISKS AND INFLUENCE}

From the current development point of view, the development of shallow oil wells has come to an end, while the oil reserving in deep strata are still relatively rich, accounting for more than $50 \%$ of Chinese oil resources, so the exploration and development of deep and ultra-deep wells will become the main direction of oil exploitation. Taking the western region of China as an example, the geological conditions are complex and the working conditions are so poor that there are many dangerous situation encountered in the drilling process. These reasons may lead to more risks and seriously affect the drilling efficiency. According to the result of investigation, the common drilling risks are touchdown, sticking, well leakage(lost circulation), hole collapse, fracture of drilling tool and drilling tool piercing and leakage and so on.Among them, the most easily occurred is sticking and touchdown. According to the analysis of drilling risk data, we can find that the proportion of sticking and touchdown is about $49 \%$, the proportion of lost circulation is about $24.5 \%$, the proportion of drilling tools failure or drilling tool piercing and leakage is $12 \%$, and that the rest factors account for about $15 \%$.

In the process of drilling, the phenomenon that drilling tools cannot move freely in wells due to various reasons is called sticking.The reasons for sticking can be summed up in the following categories:

(1)Sticking caused by the wellbore geometry: sticking caused by the change of wellbore geometry, in which the drilling fluid can cycle normally, and the drill string can only move in one direction.

(2)Sticking caused by the cuttings: this kind of sticking is mostly caused by poor wellbore cleaning leading to residual solid particles in the annular, it usually occurs when pulling out.When this kind of sticking occurs, the drilling fluid cycle will be affected, what's more, the drilling fluid will not be recycled in some serious cases.

(3)Sticking caused by the pressure difference in well: because of the pressure of the drilling fluid string, the drilling tools are pressed on the sidewall of the permeable section. The pressure difference between the two sides of the drill resulted in the failure of the drill to move[2].
The touchdown is a phenomenon that the drilling is blocked caused by the shrinking of the well diameter, the collapse of the well wall and the change of drilling fluid performance during the drilling process.

The lost circulation is a phenomenon of drilling fluid or cement leaking into the formation during drilling. It is a common and serious downhole complex situation in drilling, which will lead to the decrease of liquid column pressure in the well, the collapse of wellbore and blowout, and this is also one of the main causes of sticking.

The collapse is a phenomenon that the wellbore is sloughed off caused by the change of in-well pressure, formation complexity and other complex factors in the process of drilling.

The fracture of drilling tool is a phenomenon of the failure of drilling tools due to fatigue caused by geological conditions and pressure changes and other related factors when the drilling tool works in the well.The fracture of drilling tool may lead to the occurrence of fish, the fishing of fish and the replacement of drilling tool are time-consuming processes, so the fracture of drilling tool has a great influence on drilling efficiency.

The existence of downhole safety risks will inevitably bring a series of serious effects, which will lead to drilling difficulties, increased drilling operation time and material loss in the process of drilling operation. In some serious cases, it will also cause drilling tool fracture, leading to drilling work cannot be carried out effectively, and even cause downhole complexity, downhole fluid column pressure reduction, hole collapse and blow out and other dangerous conditions. Eventually, it will result in lost circulation and wellbore scrapping. To sum up, the risks existing in drilling will seriously affect the efficiency of oil production, increase the difficulty of drilling, and improve the risk and cost of drilling. The monitoring, analysis and prevention of drilling risk is important in drilling engineering. It is of great significance for drilling engineering to correctly evaluate the risk and effectively avoid the hidden dangers existing in the drilling engineering.

Section Conclusion: in this section, the risks and problems in drilling are introduced, the phenomena and causes of the formation of various drilling risks are clearly understood, and the serious effect of the drilling risk is described, It is helpful to reduce the occurrence of drilling accidents in engineering.

\section{WORKING PRINCIPLE OF DOWNHOLE SAFETY MONITORING SYSTEM}

The downhole safety monitoring system realizes drilling process monitoring and drilling risk prevention through the measurement of the downhole parameters. It is composed of downhole parameter measurement system, downhole data transmission and processing system and drilling risk real-time 


\section{International Journal of Engineering Applied Sciences and Technology, 2019 \\ Vol. 4, Issue 7, ISSN No. 2455-2143, Pages 10-14 \\ Published Online November 2019 in IJEAST (http://www.ijeast.com)}

assessment and analysis system(as shown in figure 1). Its working principle is to measure the dynamic parameters in drilling process through downhole tools in real time. These parameters are transmitted to the surface in real time by means of wireless pulse of drilling fluid after downhole data processing, and then these data are analyzed in real time by surface data acquisition and comprehensive analysis software to predict and evaluate the risks of downhole drilling operation, so as to give the risk hint and the measures to eliminate and reduce risk.Finally, it can realize downhole monitoring and ground control as well, effectively avoid drilling accidents and achieve risk-free drilling. At the same time of data measurement and transmission, the downhole system has the function of data storage, contributing to analyze the downhole data effectively after the downhole measuring instrument comes out of the well.

Combined with underground storage data and surface data comprehensive analysis platform, the downhole measurement system can measure downhole drilling pressure, torque, bending moment, vibration, rotational speed, annular pressure, drill string pressure, well deviation and azimuth and other parameters, and it also can comprehensively collect surface drilling pressure, rotating speed, torque, riser pressure, well depth, density, inlet displacement, outlet displacement, mud pool volume and other parameters to comprehensively analyze and evaluate the risk problems in drilling engineering.

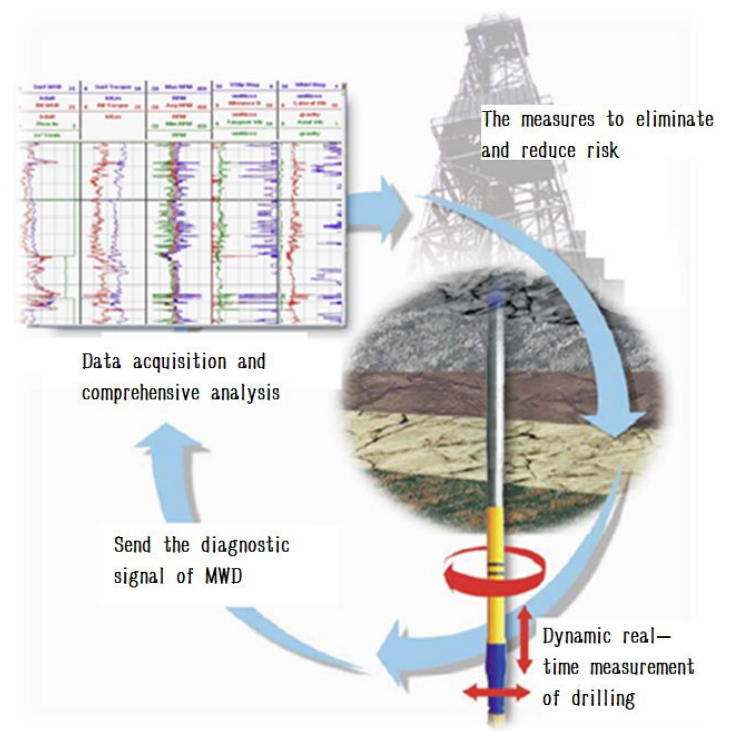

Fig. 1. Working principle of downhole safety monitoring system

Section Conclusion: in this section, the Structure composition, working principle and function of the downhole safety monitoring system are introduced, so that we can better understand the system's working mechanism, information transmission mode and so on.

\section{THE IMPORTANT ROLE OF DOWNHOLE SAFETY MONITORING SYSTEM}

In the current oil drilling, with the gradual shortage of shallow oil and gas resources, the development of deep and ultra-deep wells will occupies a dominant position. In the drilling process of deep and ultra-deep wells, there exist the characteristics of complex geological conditions, poor drillability of rock layer, low drilling speed, high bottom hole temperature, complex pressure and easy distortion of drill string[4]. Secondly, the downhole situation is complex and changeable, and the possibility of unknown risks is great, which is so easy to result in drilling safety accidents and seriously affects the efficiency and safety of drilling operations. Through research and practice, it is proved that most of the safety accidents can be effectively prevented and avoided as long as the complex conditions in the borehole are well monitored and guided. Therefore, the downhole safety monitoring system plays an important role in oil drilling safety, and it can also be said that downhole safety monitoring system is a powerful guarantee for drilling safety.

The downhole safety monitoring system includes downhole parameter measurement system, downhole data transmission and processing system and drilling risk real-time analysis system, and the control structure of the whole system is shown in figure 2. The system has the function of real-time data monitoring. There are a variety of data windows in the monitoring process. The surface data comprehensive analysis platform can display the real-time data of each measuring point in a variety of ways such as a list, a curve, an analog graph and so on, these real-time data including various monitoring parameters, such as the positions of measuring point, monitoring data and so on. The core technology of downhole safety monitoring system mainly realizes the real-time control of downhole drilling tool state and wellbore condition through the real-time monitoring of many drilling parameters, such as drilling pressure, torque, drilling speed, pressure and so on, so as to ensure the safety of downhole drill string and wellbore, and to reduce the complexity of drilling, provide technical support for drilling safety. At the same time, based on the theory of mechanical specific energy, optimizing the drilling parameters in real time and increasing the drilling speed guarantee that the drilling operation is carried out safely and quickly and greatly speed up the exploration and development of complex wells such as deep and ultra-deep wells. 


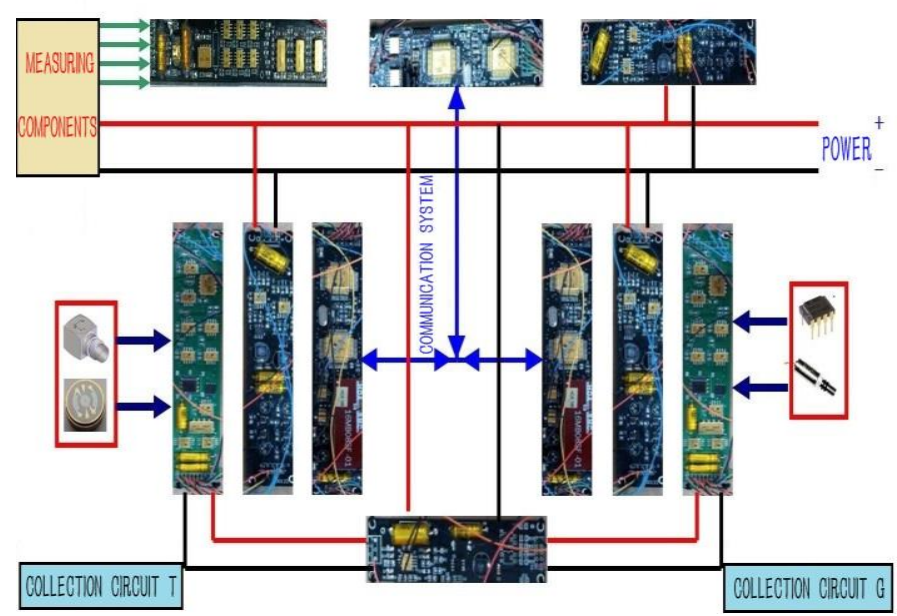

Fig. 2. Control structure of downhole safety monitoring system

The downhole safety monitoring system can evaluate the efficiency of underground rock carrying through the monitoring of annular pressure, it can be used to evaluate the accumulation of cuttings at the bottom of the hole and the safety of drilling. By the monitoring of drill string pressure, the risks of bit balling and drill string piercing leakage can be judged in time. Serious downhole drill string vibration may cause serious problems such as tripping, premature wear of drill bit, decrease of drilling speed and failure of measurement while drilling $(M W D)$ tool and bottom hole assembly(BHA). It is particularly difficult to diagnose the dangerous downhole transverse vibration on the ground, only by monitoring the vibration in real time can we predict and judge the real-time working condition of the drilling tool to achieve the aims of analyzing the existing problems effectively and avoiding the occurrence of the drilling tool accident. By the monitoring of downhole drilling speed, the diagnosis of downhole viscous slip can be carried out. By the monitoring and measurement of drilling pressure and torque, the elastic deformation of drilling pressure and torque transmitted by drill string can be quantified, the performance of drill string can be effectively analyzed, and the safety of drill string can be ensured. The bending moment distribution on the bottom hole assembly (BHA) is related to the lateral force of the bottom hole assembly at each contact point(drill bits, centralizers, tool joints, etc.) in the hole. The downhole bending moment increases with the increase of wellbore curvature, and the change of wellbore trajectory can be determined by the monitoring of bending moment. The dynamic change of drill string can be monitored by measuring drilling pressure, bending moment and torque. Through the direct measurement, real-time transmission and comprehensive analysis of the mechanical and engineering parameters of the near bit, the automatic alarm of drilling risk and the indication of the direction of parameter optimization are realized.

Through the analysis and evaluation before drilling and the monitoring with drilling, the downhole safety monitoring system contributes to safely and rapidly drilling, which reduces drilling accidents and protects the property safety of the country and the people to a great extent. In conclusion, the system integrates several technologies such as downhole measurement, transmission and analysis, realizing the visual monitoring of drilling process and the intelligent monitoring and prediction of drilling risk, which plays a positive role in ensuring downhole safety, reducing drilling complexity, improving drilling efficiency and saving drilling cost. The successful application of downhole safety monitoring system accelerates the development of oil drilling exploration and production technology in our country, and provides effective technical support for safe and rapid drilling, especially for the exploration and development of complex wells such as deep wells and ultra-deep wells, and becomes an effective weapon that can reduce the complexity of drilling and ensure the safety and speed of drilling.

Section Conclusion: in this section, the application background of the downhole safety monitoring system and the great demand in the industry are introduced. The functions of each component system in the downhole safety monitoring system are described, and the mechanism of action is understood. It reflects the powerful function and determines its important role in the drilling process.

\section{CONCLUSION}

Petroleum resources are the basis of national development. The combination of excellent technology and safe development environment can ensure the exploitation efficiency of oil and gas resources. Based on the analysis of the present situation of energy development in China, the deep exploitation of oil and gas resources will be the inevitable trend of the later development, it is mainly represented by the exploitation of deep and ultra-deep wells, which are difficult to develop with many downhole complex conditions. Compared with the exploitation of shallow oil in the early stage, the deep exploration and development operation has higher requirements for machinery, environment, geology and so on. In order to ensure the safety, speed and efficiency of oil drilling, the real-time monitoring of downhole complex conditions is an important part of drilling engineering, and downhole safety monitoring system plays an important role in oil drilling.

In the course of drilling, comprehensive the downhole parameter measurement system, downhole data transmission and processing system and drilling risk real-time analysis system paying close attention to the dynamic change of downhole parameters, effectively analyzing and processing the working condition data of drilling tools, predicting and evaluating the possible safety risk problems, and giving full play to the functionality of downhole safety monitoring system are all the keys to improve drilling safety.

Through the application of downhole safety monitoring system, the mechanical operation efficiency and technology of oil exploitation can be improved, and the safety risk in drilling process can be prevented and controlled, which can more 


\section{International Journal of Engineering Applied Sciences and Technology, 2019 \\ Vol. 4, Issue 7, ISSN No. 2455-2143, Pages 10-14 \\ Published Online November 2019 in IJEAST (http://www.ijeast.com)}

effectively improve drilling efficiency, ensure drilling safety and promote the green development of petroleum drilling engineering.

\section{ACKNOWLEDGEMENT}

First of all, this paper is completed on the basis of the research of many experts and scholars in the field of industry, the research results of experts and scholars have given me a lot of help, thank you very much to the researchers in the field of related industries. Secondly, I would like to thank my mentor for his teaching and careful guidance, as well as my colleagues for their help in the work of the paper. Finally, I would like to pay special tribute to the international journal of engineering applied sciences and technology for giving me the opportunity.

\section{REFERENCE}

[1] Lu Shuanlu, Li Helin, Fujiu Xueqing, etc. (2011). Review on failure analysis of casing fastening and leakage [J]. Oil mine machinery, (Pg21-25).

[2] Long Zhihui, Zhang Jinhong. (2010). Drilling engineering. Beijing: Sinopec Press.

[3] Steve Devereux.(2012).Drilling Technology in Nontechnical Language, 2d Ed.PennWell Corp.

[4] Hou Zhijiang.(2019).Technical difficulties and Countermeasures of Speed increase in Deep well and Ultra Deep well drilling [J]. Chinese Petroleum and Chemical Standards and quality, (Pg101).

[5] Wang Xiaolei, Miao Lei. (2018). Present situation and development trend of oil drilling technology in China [J]. Chemical Design Newsletter, (Pg223-234).

[6] Bai Fangzheng. (2018). The present situation and trend of the development technology of petroleum and natural gas in china[J]. Petrochemical Technology, (Pg213).

[7] Zhang Zhiliang, Yi Ming, Deng Boyi, Hu Ziwei, Long Jianhua. (2019). Field test and application of underground safety monitoring system $[\mathrm{J}]$. New technology and new process, (Pg57-60).

[8] Zhang Heng, Wang Guangxin, Li Ruiying. (2009). Application feasibility of NDS drilling technology in daqing oilfield [J].Western Prospecting Project, (Pg62).

[9] Zhang Weidong, He Delei, Yuan Wenkui, Huang Jie. (2010). The key technology of risk-free drilling and its application [J]. Oil drilling Technology, (Pg53).

[10] Zhang Sanbao.(2019). Analysis of research status and development trend of mine safety monitoring system [J]. Mechanical and Electrical Engineering Technology, (Pg157-159).

[11] Zang Xiaoyu, he Yaqiong.(2019). Explore vertical drilling techniques for deep wells, ultra-deep wells and complex structural wells [J]. Corporate Culture.
[12] Jia Hokun, Zhang Shuang, Jiang Feng.(2016). Analysis and Development Strategy of Chinese Oil Present Situation[J]. Engineering Technology, (Pg44).

[13] Zhang Shaohuai. (2005). Vertical drilling technology of deep, ultra-deep well and complex structure[J]. Petroleum drilling technology, (Pg14-18). 